\title{
TISSUE ENGINEERING: FROM RESEARCH TO CLINICAL APPLICATION IN REGENERATIVE MEDICINE
}

\author{
ENRICO TOGNANA *, LANFRANCO CALLEGARO *
}

ABSTRACT. - Tissue engineering strategies have recently emerged as the most advanced therapeutic option presently available in regenerative medicine. Tissue engineering encompasses the use of cells and their molecules in artificial constructs that compensate for lost or impaired body functions. It is based upon scaffoldguided tissue regeneration and involves the seeding of porous, biodegradable scaffolds with donor cells, which become differentiated and mimic naturally occurring tissues. These tissue-engineered constructs are then implanted into the patient to replace diseased or damaged tissues. Our approach to regenerative medicine is based on hyaluronan derivative polymers.

$\mathrm{HYAFF}^{\circledR}$ is a class of hyaluronan derivative polymers obtained by coupling reaction. The strategy behind the creation of these polymers was to improve the stability of the polymer by esterifying the free carboxyl group of glucuronic acid, frequently repeated along the hyaluronic acid chain, with different types of alcohols. Once esterification of the polymer has been obtained, the material can easily be processed to produce membranes, fibres, sponges, microspheres and other devices, by extrusion, lyophilization or spray drying. A broad variety of polymers can be subsequently generated either by changing the type of ester group introduced or the extent of the esterification. The benzyl esters of hyaluronan, termed HYAFF ${ }^{\circledR}-11$, are one of the most characterized HYAFF ${ }^{\circledR}$ polymers, from both the physicochemical and biological viewpoints, produced starting from hyaluronan of about $200 \mathrm{KDa}$.

The ideal scaffold for tissue engineering should provide an immediate support to cells and have mechanical properties matching those of the tissue being repaired. Gradually then the material should be resorbed, as the cells begin secreting their

* Fidia Advanced Biopolymers S.r.l. 
own extracellular matrix, thus allowing for an optimal integration between newformed and existing tissue. Extensive biocompatibility studies have demonstrated the safety of $\mathrm{HYAFF}^{\circledR}$ scaffolds and their ability to be resorbed in the absence of an inflammatory response. Moreover, when implanted tend to promote the recapitulation of the events that facilitate tissue repair.

$\mathrm{HYAFF}^{\circledR}-11$ three-dimensional matrices support the in vitro growth of highly viable chondrocytes and fibroblasts. Similarly, micro-perforated membrane supports the growth and differentiation of keratinocytes. These cells, previously expanded on plastic and hence seeded into the HYAFF ${ }^{\circledR}$ scaffold, produce a characteristic extracellular matrix rich in proteoglycans expressing the typical markers of the tissues of their origin.

Hyaluronan presents a variety of multi-functional activity being both a structural and informational molecule. Investigation of hyaluronan synthesis and degradation, the identification of new receptors and binding proteins and the elucidation of hyaluronan-dependent signaling pathways keep providing novel insights into the true biological functions of this intriguing polymer. The possibility to elaborate this natural polymer in different physical forms, as $\mathrm{HYAFF}^{\circledR}$ biopolymers family is allowing to do, has given the opportunity to translate tissue engineering strategies in clinical practice providing a biomaterial that induces and modulates the sequence of events that lead to damage tissue restoration.

The following chapter will report how tissue engineering approach and hyaluronic acid technology could improve the biological function of cell transplantation in the treatment of tissue defects, in particular for skin and cartilage tissue restoration.

\section{INTRODUZIONE}

La definizione forse più completa di ingegneria dei tessuti è quella di Langer e Vacanti, i quali si riferirono all'ingegneria dei tessuti come ad un settore interdisciplinare che applica i principi dell'ingegneria e delle scienze della vita per lo sviluppo di sostituti biologici che ripristinano, mantengono o migliorano le funzioni dei tessuti (Langer e Vacanti, 1993). Questo intrigante campo della ricerca prevede l'utilizzo di biomateriali sui quali vengono seminate e coltivate le cellule. L'ingegneria dei tessuti è un importante ambito di ricerca a carattere interdisciplinare che offre prospettive terapeutiche innovative volte a superare i limiti del trapianto e della protesi e quindi a migliorare la qualità della vita di milioni di persone. Infatti, nonostante i notevoli progressi nel campo della chirurgia dei trapianti e dell'ingegneria biomedica, la perdita o il danneggiamento di un organo o tessuto rimangono un problema aperto per la medicina moderna, soprattutto a causa della scarsità di organi a disposizione. A ciò si 
aggiungono le difficoltà di conservazione degli organi, i problemi di tipo immunologico (si considerino i danni dei trattamenti immunodepressivi cronici), ed infettivologico (si pensi ai prioni), le difficoltà tecniche di carattere chirurgico e i costi tuttora molto elevati.

Il tissue engineering consente, invece, la creazione di sostituti biologici funzionali e compatibili, in grado di ripristinare la struttura danneggiata o mancante. È opportuno precisare che l'ingegneria dei tessuti è volta alla creazione in vitro di tessuti qualitativamente e quantitativamente idonei a sopperire alle necessità cliniche, superando in tal modo i limiti dei biomateriali eubiotici (da esseri viventi) e dei biomateriali xenobiotici (di origine sintetica). Infatti i primi, pur vantando un'ottima biocompatibilità, sono limitati in quantità e rappresentano un possibile veicolo di trasmissione di infezioni. I secondi, invece, nonostante presentino una maggiore disponibilità quantitativa, posseggono una minore biocompatibilità.

La definizione più ampiamente accettata della ingegneria dei tessuti la caratterizza come l'applicazione dei principi e dei metodi delle scienze della vita e dell'ingegneria per la comprensione fondamentale delle relazioni tra struttura e funzione nei tessuti normali e patologici di mammiferi, e per lo sviluppo di sostituti biologici che ripristinino, mantengano o migliorino le funzioni dei tessuti (Skalak e Fox, 1988).

È qui opportuno enfatizzare l'interdisciplinarietà di questa importante branca della ricerca, poiché lo sviluppo di un costrutto ingegnerizzato richiede l'integrazione di competenze di varie discipline, dalla biologia, alla medicina, dalla chirurgia, alla chimica, dall'ingegneria alle scienze dei materiali e alla robotica.

Il tissue engineering può essere considerato l'ambito più promettente del nuovo capitolo della chirurgia moderna, la cosiddetta chirurgia rigenerativa o regenerative medicine.

Di seguito verranno schematizzati i principi fondamentali della ingegneria dei tessuti e le sue applicazioni industriali in campo biomedico basandosi sull'esempio dello sviluppo ed applicazione di scaffold a base di acido ialuronico.

\section{LE STRATEGIE DELLA INGEGNERIA DEI TESSUTI}

L'ingegneria dei tessuti prevede l'utilizzo di cellule isolate coltivate in vitro su adeguate matrici (scaffold). Per specifici impieghi di ricostruzione di strutture con particolari caratteristiche biomeccaniche, o in 
caso di vere e proprie sostituzioni d'organo, è possibile pensare alla realizzazione di matrici ingegnerizzate sulle quali far attecchire i tipi cellulari propri del tessuto da ricostruire, ad esempio cartilagine, cute od osso (Donati, 2001; Goodbey e Atala, 2002).

È questo l'approccio sicuramente più diffuso e più promettente e che viene, in effetti, generalmente identificato con il termine tissue engineering. Esso prevede quindi l'utilizzo di biomateriali, usati come scaffold (impalcature di supporto) e di cellule viventi. Possono venire aggiunte, inoltre, molecole biologicamente attive, quali i fattori di crescita, per facilitare la crescita e il differenziamento della componente cellulare.

In tal modo vengono sfruttate sia le caratteristiche meccaniche e strutturali dei biomateriali, sia le capacità biologiche delle cellule e delle molecole bioattive, al fine di ottenere sostituti capaci di interagire con l'organismo ospite, vicariando funzioni carenti, o modulando fenomeni biologici quali, ad esempio, la crescita e la reattività tessutale.

I risultati delle ricerche nel campo del tissue engineering possono trovare impiego in molteplici settori della medicina e della chirurgia, in qualunque situazione in cui una funzione dell'organismo risulti mancante o deficitaria.

Per lo sviluppo di sostituti biologici in grado di integrarsi con l'organismo ospite, anatomicamente e funzionalmente, è necessario affrontare alcune problematiche, che, come già sottolineato, non potranno essere risolte se non attraverso un approccio interdisciplinare spaziante dalla biologia all'ingegneria dei materiali. Tali questioni, affrontate più diffusamente nei prossimi capitoli, riguardano fondamentalmente: i) l'identificazione di materiali rigorosamente biocompatibili che permettano l'attecchimento, la crescita, e la differenziazione cellulare e che siano "ingegnerizzabili", nei modi tridimensionali necessari ed accetti sia alle cellule sia all'organismo ricevente; ii) l'affinamento di tecniche di isolamento, conservazione e coltura in vitro dei ceppi cellulari necessari di varia origine, incluse le cellule staminali; iii) la collocazione da un punto di vista legislativo, bioetico e normativo di tali nuovi sostituti biologici.

\section{BIOMATERIALI A BASE DI ACIDO IALURONICO}

L'ingegneria tessutale non può prescindere dallo sviluppo di biomateriali, in quanto essi sono indispensabili per lo sviluppo delle cellule in 
ambiente tridimensionale, condizione necessaria per il raggiungimento di un'organizzazione spaziale simile a quella esistente nei tessuti nativi (Cima et al, 1991).

Negli ultimi anni, di pari passo con l'evoluzione delle conoscenze biomediche, con il perfezionarsi delle tecniche chirurgiche e con l'aumento della vita media, l'uso dei biomateriali in medicina ha avuto uno sviluppo tale da poterli considerare come uno degli elementi chiave nella rivoluzione tecnico-chirurgico-terapeutica alla quale stiamo assistendo. È negli ultimi anni, infatti, che si è introdotta la definizione di biomateriali per indicare qualunque materiale non vitale, di origine naturale o prodotto artificialmente, utilizzato per dirigere, supplire o rimpiazzare le funzioni specifiche dei tessuti viventi.

È opportuno specificare che i biomateriali, per essere considerati tali, devono interfacciarsi in qualche punto con un tessuto vivente o con i fluidi biologici. Oggigiorno i biomateriali vengono utilizzati continuamente nella pratica medico-chirugica, basti pensare ai comuni fili di sutura, e sono ormai innumerevoli i componenti dell'organismo che possono essere ultimamente sostituiti da biomateriali; si va dai sostituti ossei e cartilaginei utilizzati in ortopedia alle valvole cardiache, alle protesi vascolari alle lenti a contatto, alle resine dentali, ai sostituti cutanei.

In generale, biomateriali utilizzati nel tissue enginering possono essere suddivisi in tre classi principali: naturali, semisintetici e sintetici. I biomateriali naturali maggiormente usati sono generalmente di natura proteica (come, ad esempio, il collageno di origine bovina o porcina e la fibrina) o polisaccaridica (come, ad esempio, l'acido ialuronico).

Il biomateriale ideale deve essere capace di interagire sia con le cellule, supportandone la crescita e la produzione dei componenti della matrice extracelluare, sia, in generale, con l'ambiente in cui vengono impiantati. Contemporaneamente il biomateriale deve essere degradato, lasciando spazio alla crescita di altre strutture, come ad esempio i vasi, garantendo quindi la piena integrazione del costrutto ingegnerizzato. Un esempio di biomateriale di questo tipo è dato dagli esteri dell'acido ialuronico $\left(\mathrm{HYAFF}^{\circledR}\right)$.

L'acido ialuronico è un glicosaminoglicano distribuito nello spazio extracellulare e specialmente nella matrice extracellulare (Fig. 1). 


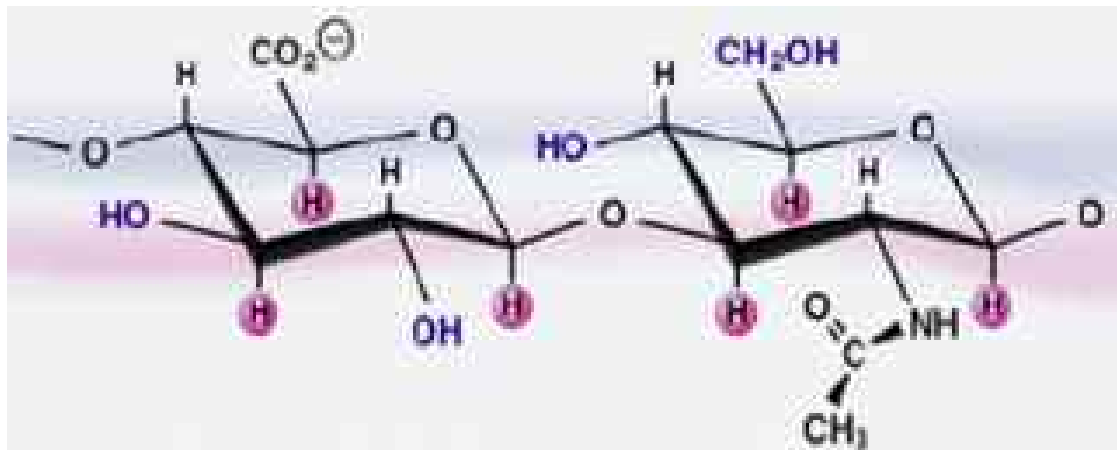

Fig. 1.

Lo schema mostra la struttura dell'acido ialuronico. I biopolimeri HYAFF ${ }^{\circledR}$ si ottengono sostituendo con reazione chimicamente di esterificazione $i$ gruppi-OH con gruppi alcolici.

È un polimero lineare formato da unità di-saccaridiche non-sulforate che si ripetono regolarmente con un peso molecolare che può variare da 4000 a $8 \times 10^{6}$ Da.

Soprattutto, presenta una struttura molecolare rimasta immutata durante l'evoluzione a rivelarne l'estrema importanza fisiologica. Forma un gel altamente viscoso in acqua e gioca un ruolo fondamentale nella biologia cellulare e dei tessuti sia per le sue proprietà biologiche che fisiche. Data la sua natura riesce ad interagire con specifici ligandi (proteine, proteoglicani, molecole biologicamente attive) influenzando l'interazione cellulare. È evidente che la presenza di specifici recettori (e.g. CD44, RHAMM) permette di modulare la presenza di acido ialuronico in modo sito-specifico e di conseguenza influenza il modellamento dei tessuti. Di notevole importanza sono anche gli oligomeri che si liberano dalla degradazione dell'acido ialuronico, anch'essi con delle specifiche proprietà biologiche a seconda del peso molecolare. Di recente è stato infatti osservato come tali oligomeri abbiano sia una funzione condropenica che sulla vascolarizzazione. Inoltre, da anni l'acido ialuronico è usato nella pratica clinica come agente visco-supplementante delle articolazione sinoviali ed in applicazioni oftalmiche delineando un alto profilo di sicurezza.

Di conseguenza appare evidente come l'acido ialuronico possa venir considerato, sotto molti punti di vista, il biomateriale ideale nell'applicazione delle strategie della ingegneria dei tessuti. Lo sco- 
glio maggiore nell'utilizzare con successo nelle strategie della ingegneria dei tessuti l'acido ialuronico è proprio la sua caratteristica conformazione in stato di gel quando si trova nella sua forma più pura. Il fatto di essere solubile in acqua e di avere una bassa permanenza in vivo, in quanto prontamente riassorbito, ne limitano fortemente l'utilizzo in medicina rigenerativa. Cross-linking e reazioni di accoppiamento sono due delle tecniche possibili per ottenere una forma stabile di acido ialuronico. Utilizzando infatti queste tecniche biochimiche risulta possibile migliorare la sua processazione. I derivati dell'acido ialuronico possono quindi essere estrusi a produrre fibre e membrane o liofilizzati in modo da ottenere spugne e microsfere. Le fibre quindi possono essere lavorate in garze, fili o anche tessuto non-tessuti (Fig. 2).

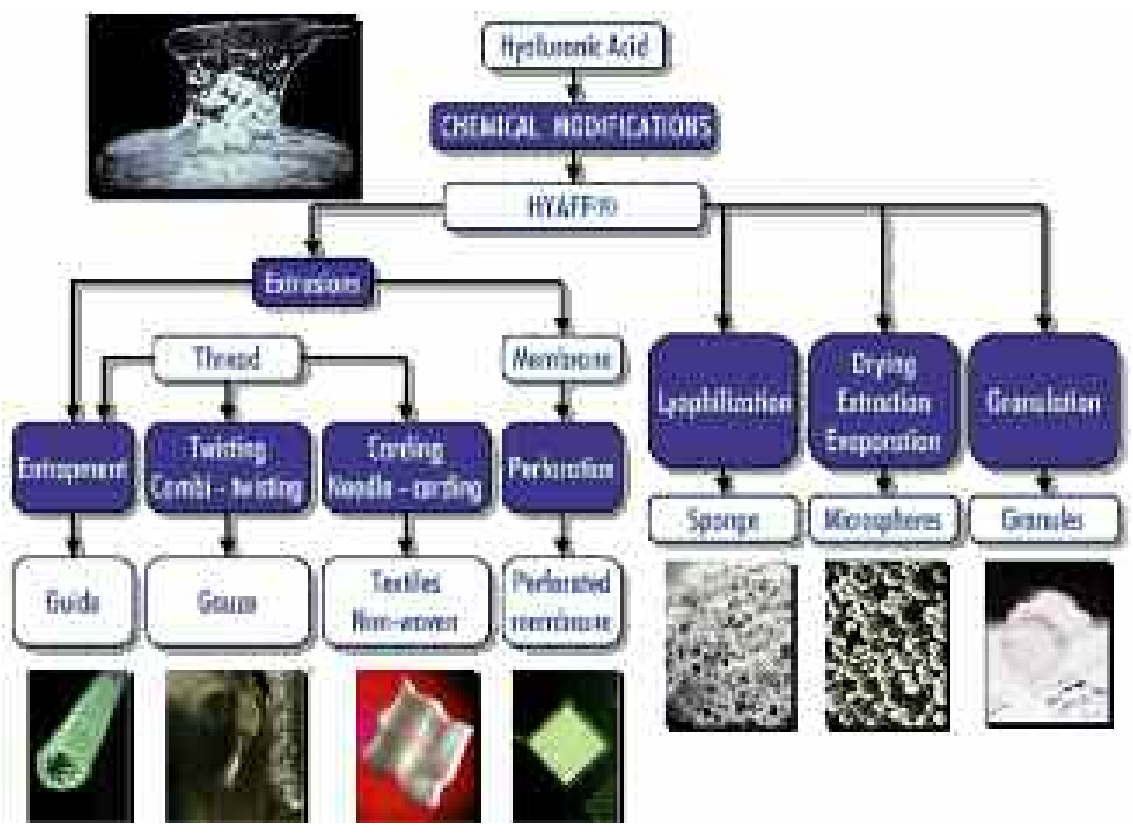

Fig. 2.

Lo schema mostra come dall'acido ialuronico (in stato di gel nella sua forma più pura) si riesca, grazie alle proprietà chimico-fisiche della famiglia dei biopolimeri HYAFF ${ }^{\circledR}$, ad ottenere dei materiali altamente biocompatibili con le più diverse geometrie, dalle fibre e membrane alle spugne e microsfere. 
Con la possibilità di avere l'acido ialuronico in una forma più stabile ha di fatto reso questa molecola una delle più promettenti nelle applicazioni biomediche.

In quest'ottica $\mathrm{HYAFF}^{\circledR}$ è una classe di derivati dell'acido ialuronico ottenuti per reazione di accoppiamento. La strategia sottesa alla creazione di questo polimero semi-sintetico è stata quella di migliorare la stabilità dell'acido ialuronico esterificandone il gruppo glucuronico con dei gruppi alcolici. A seguito di questa modifica chimica si ottiene la riduzione della componente idrofilica con una concomitante incremento delle proprietà idrofobiche dell'acido ialuronico. Inoltre, cambiando la percentuale ed il tipo di esterificazione è possibile creare un'ampia varietà di polimeri con consistenza e tempi di residenza in vivo modulabile. Della famiglia dei derivati dell'acido ialuronico lo HYAFF $^{\circledR}$-11 è quello maggiormente caratterizzato, sia dal punto di vista fisico-chimico che da quello biologico. Viene prodotto da acido ialuronico con peso molecolare di 200.000 Dalton che viene esterificato totalmente con alcol benzilico. Su tale molecola sono stati fatti estesi studi che ne hanno dimostrato la assoluta sicurezza ed il suo totale riassorbimento in assenza di risposta infiammatoria (Campoccia, 1998). Più di recente è stato poi ipotizzato che i biomateriali a base di HYAFF $^{\circledR}$ riescano a mimare l'ambiente embrionale, ideale per lo sviluppo delle cellule progenitrici, fornendo un'alta concentrazione di acido ialuronico nel sito di impianto. Inoltre, quando matrici a base di $\mathrm{HYAFF}^{\circledR}$ vengono veicolate nel difetto tendono a promuovere quegli eventi che facilitano la riparazione tessutale (Caplan, 2000).

\section{CELlule E TECNICHE DI COLTURA IN VITRO}

Il tissue engineering, oltre alla componente strutturale, prevede l'impiego di una o più componenti cellulari. Si possono utilizzare sia cellule differenziate e specializzate, ovvero cellule che hanno raggiunto il loro scopo finale (cellule mature) sia cellule non specializzate, capaci di dare origine a tutte le popolazioni cellulari di uno o più tessuti (cellule staminali). Generalmente un tessuto vivente maturo è costituito da cellule altamente differenziate e specializzate, con capacità riproduttiva variabile.

A differenza delle colture cellulari su larga scala, che riguardano più spesso cellule indifferenziate o trasformate o comunque stipiti cellulari che facilmente si mantengono e proliferano in vitro, le cellule ne- 
cessarie nei procedimenti di ingegneria tessutale sono spesso difficilmente coltivabili, hanno complesse richieste nutrizionali, e sono molto sensibili ad una vasta gamma di agenti lesivi.

Rispetto alle tecniche chirurgiche tradizionali, l'ingegneria tessutale permette una notevole amplificazione della quantità di tessuto disponibile, grazie all'espansione in vitro delle cellule componenti il tessuto stesso. Gli esempi indicati si riferiscono a cute e cartilagine ingegnerizzata, considerando un impiego autologo di tali tessuti (Fig. 3).

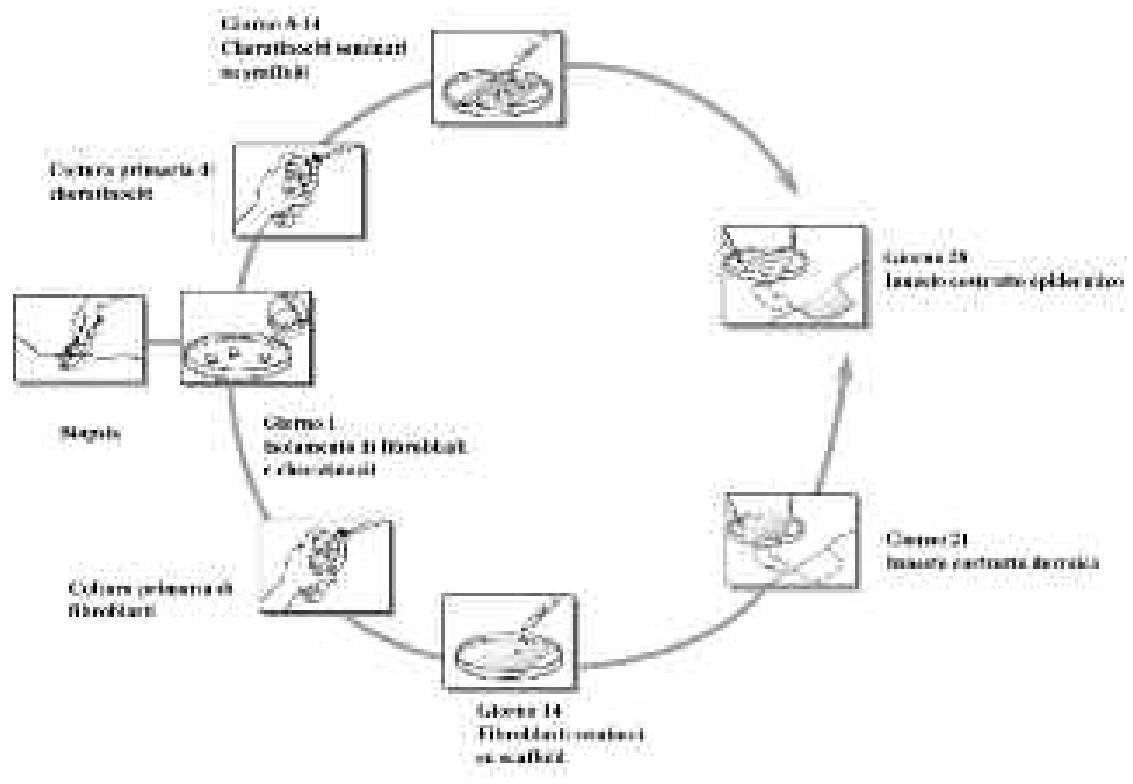

Fig. 3 .

TissueTech Autograft System ${ }^{\mathrm{TM}}$ : la logistica del tissue engineering.

Il diagramma mostra le diverse fasi sulle quali si basa l'ingegneria dei tessuti prendendo ad esempio la cute ingegnerizzata. Dall'atto iniziale della biopsia del tessuto si passa alla dissociazione delle cellule dalla matrice tessutale e quindi alla loro espansione in vitro in 2D prima di essere seminate sulla scaffold tridimensionale. Di seguito è l'innesto del costrutto (cellule-scaffold) nel paziente.

Il POT (Population Doubling Time, tempo medio di replicazione) e il numero di cellule iniziale determinano il tasso di espansione e quindi la quantità di tessuto ingegnerizzato ottenibile in un tempo definito. Nel caso della cute ad esempio, da un prelievo bioptico di $1 \mathrm{~cm}^{2}$ vengono 
isolate le due componenti cellulari (fibroblasti e cheratinociti). Dopo circa 23 giorni, la superficie dell'epidermide ingegnerizzata prodotta risulta quintuplicata rispetto alla componente dermica, ciò è dovuto a due ordini di motivi. Innanzitutto i cheratinociti si dividono in coltura più velocemente rispetto ai fibroblasti; inoltre il numero di cheratinociti isolati dalla biopsia è ben superiore al numero dei fibroblasti recuperati (Fig. 3).

Nel caso della cartilagine, si considera un prelievo di circa $150 \mathrm{mg}$ di tessuto, corrispondente a circa 200.000 cellule isolate. Il numero di cellule ricavabili da tale prelievo, dopo la fase di espansione in vitro, può essere sufficiente per ricoprire l'intera superficie del condilo articolare.

Nei due casi considerati, le tecniche tradizionali, prevedendo l'impiego di tessuto autologo, comportano una lesione al sito donatore, la cui gravità dipende, ovviamente, dalla quantità di tessuto prelevato. In caso di ulteriore necessità, il sito di prelievo non è più disponibile per successive "raccolte" della stessa qualità. I prelievi tessutali necessari per produrre un costrutto autologo ingegnerizzato sono invece estremamente ridotti, poco invasivi, e non deturpanti sotto il profilo estetico o funzionale.

Inoltre, per una soddisfacente coltivazione ed amplificazione di una popolazione cellulare è fondamentale l'identificazione di terreni di coltura ideale che forniscano alle cellule le sostanze necessarie alla loro proliferazione e differenziazione. Essi possono essere costituti da semplici nutrienti o da una, complessa combinazione di fattori di crescita. Qualunque sia il tipo cellulare interessato è, quindi, possibile adottare degli accorgimenti nelle condizioni di coltura per stimolare la proliferazione e modificare il medium per fare in modo che le cellule esibiscano un fenotipo stabile e funzionale. La composizione di tali terreni di coltura è del tutto differente a seconda del tipo cellulare interessato e la loro descrizione, non utile in questo contesto, è in evoluzione continua.

Il microambiente esistente in vivo è presumibilmente quello ottimale per la crescita e la differenziazione cellulare, sarebbe quindi auspicabile ricrearlo in vitro; ma non tutti i suoi componenti ci sono noti.

Per questi motivi è soddisfacente il poter riprodurre solamente le condizioni ambientali più critiche per la proliferazione degli elementi cellulari considerati. Bisogna ricordare come un presupposto fondamentale per l'ottenimento di un tessuto artificiale funzionale sia che le cellule interessate mantengano la loro specifica funzione, la quale è 
strettamente correlata alla morfologia ed in particolare alla conformazione funzionale della membrana. Questo aspetto si è rivelato particolarmente critico per quei tipi cellulari con funzioni molto complesse quali gli epatociti, ma anche per la stratificazione dei cheratinociti. Alcuni Autori considerano inoltre fondamentale lo studio delle forze fisiche che agiscono all'interno delle colture cellulari. Si è infatti scoperto che la disposizione tridimensionale o l'applicazione di stress meccanici influenzano grandemente la proliferazione di determinati tipi cellulari ed il mantenimento della loro efficienza funzionale. Ad esempio, recenti studi hanno dimostrato come la compressione dinamica sulla cartilagine stimola la produzione di matrice extracellulare (VunjakNovakovic et al, 1999) e che uno stress unidirezionale induce l'allungamento delle cellule endoteliali. Questi fenomeni hanno stimolato la ricerca di metodiche che potrebbero essere impiegate in vitro per migliorare la maturazione tessutale. Infatti, i condrociti che, seminati su un substrato di materiale plastico, sono in grado di proliferare e secernono una notevole quantità di collageno di tipo I e piccoli proteoglicani non presenti nella cartilagine nativa. Le stesse cellule trasferite su matrice tridimensionale esprimono nuovamente il normale fenotipo evidenziabile in vivo che è caratterizzato dalla produzione soprattutto di collageno di tipo II e dalla deposizione di grossi aggregati di proteoglicani.

Le cellule delle lamine di cheratinociti coltivati in vitro non sono ben differenziate, ma l'esposizione all'aria, mentre sono ancora in coltura o dopo l'innesto, induce una differenziazione con evidenziazione dei normali strati epidermici e attivazione del fenomeno di produzione della cheratina.

Nella sezione seguente si riportata l'esperienza nel campo dei sostituti cutanei e dei sostituti della cartilagine articolare ad esempio dell'applicazione in clinica della tecnologia dell'acido ialuronico e delle strategie della ingegneria dei tessuti.

\section{APPLICAZIONI CLINICHE}

Oggi, a circa un ventennio dall'inizio degli studi sul tissue engineering, possiamo distinguere tra quanto sembrava un sogno o un'ipotesi difficilmente realizzabile e quanto invece, per concorde opinione degli esperti, è già entrato, a pieno titolo, nella nostra pratica clinica. 
Di là da scetticismi immotivati ed euforia priva di basi, oggi siamo già in grado di porre delle indicazioni precise alla luce di quello che è ormai diventato il nostro metro di misura, la cosiddetta Evidence Based Medicine (EBM). Nell'interpretazione critica fornita dal Centro Italiano per la Medicina Basata sulle Evidenze, l'EBM costituisce la ricerca - metodologicamente corretta - della migliore soluzione possibile di un problema clinico, tramite le prove di efficacia più salde emerse dalla letteratura biomedica, raccolte e interpretate criticamente alla luce dell'esperienza e dell'abilità del medico, in funzione dell'assistenza mirata al singolo paziente incontrato nella pratica clinica quotidiana, in un'ottica di rischio/beneficio e di costo/efficacia.

Attraverso la valutazione critica delle evidenze cliniche sull'impiego dei sostituti cutanei ingegnerizzati (TissueTech Autograft System $^{\mathrm{TM}}$ ), un panel di esperti diabetologi ha proposto un "Protocollo di impiego dei sostituti cutanei autologhi nel trattamento delle ulcere del piede diabetico" (Faglia et al, 2002), che costituisce un valido strumento, frutto dell'ingegneria tessutale, che può trovar posto appunto nella nostra pratica clinica.

Come già accennato, di seguito verranno delineate le applicazioni cliniche del tissue engineering che sono ormai entrate nella pratica clinica routinaria e che sono principalmente mirate alla ricostruzione della cute e della cartilagine articolare.

Dalle prime esperienze, frutto di ricerche sviluppate in laboratori ospedali eri o universitari, si è oggi passati a realtà di produzione industriale con norme, protocolli, certificazioni e sistemi di qualità (marchio CE, norme della serie ISO 9000 ed EN 29000/46000 ecc.). Ciononostante, non è ancora stato elaborato un quadro normativo spedfico per i prodotti del tissue engineering che attualmente, a seconda dei Paesi europei, generalmente ricadono nell'ambito delle regolamentazioni esistenti sui dispositivi medici - direttiva 93/42/EEC e successive modificazioni-, o sui prodotti medicinali - direttiva 2001/83/CE (per un approfondimento degli aspetti normativi si rimanda al capitolo 7 "La normativa e la bioetica") -.

Grazie ai formidabili progressi compiuti dall'ingegneria tessutale, essa viene oggi ritenuta l'ambito più promettente del nuovo ed affascinante capitolo della chirurgia moderna: la cosiddetta "chirurgia rigenerativa" o inductive surgery che, secondo Joseph E. Murray, premio nobel per la medicina nel 1990, rappresenta un superamento di quello che egli definisce the period of transplantation. 
D'altro canto la chirurgia induttiva, (Murray, 2001), permette di superare i limiti del trapianto, dovuti essenzialmente alla scarsità di tessuti ed organi disponibili. Infatti, nonostante l'aumento delle donazioni di organi, che in Italia si attestano a 17,6 per milione di abitanti (dati aggiornati ad agosto 2002), i pazienti in lista d'attesa nel nostro Paese sono ben 10.000 .

È opportuno infine sottolineare il fondamentale contributo della Scuola Italiana, senza il quale molti degli importanti risultati raggiunti nell'innovativo settore del tissue engineering non sarebbero probabilmente stati possibili (Abatangelo e Wiegel, 2000; Donati et al., 2003).

\section{CUTE INGEGNERIZZATA}

La riparazione cutanea è stata il primo campo di applicazione delle tecniche di tissue engineering, ed è tuttora il settore in cui i prodotti dell'ingegneria tessutale sono più numerosi e maggiormente diffusi in ambito clinico. D'altro canto le necessità cliniche sono rilevanti: annualmente, 6.000 persone in Europa e Nord America (1/100.000 abitanti), vengono ricoverate per ustioni di terzo grado. Analogamente, ogni anno circa 800.000 pazienti diabetici nelle stesse aree geografiche (1/800 abitanti) ricorrono a visite mediche per ulcere al piede di difficile guarigione; circa 1.500.000 di pazienti (1/400 abitanti) sono afflitti da ulcere croniche di altra natura e oltre 3.000.000 di pazienti soffrono di piaghe da decubito.

La possibilità di riparare estese soluzioni di continuo a livello cutaneo ha sempre costituito un problema di vitale importanza in medicina; infatti la perdita di integrità dell'organo deputato alla protezione dagli insulti esterni espone l'organismo ad una serie innumerevole di rischi di perdita dell'omeostasi, nonché di aggressione da parte di microrganismi (Fig. 4).

Nella pratica chirurgica tale condizione si presenta continuamente; ma una situazione estrema è rappresentata dalle ustioni estese. La soluzione fino ad ora maggiormente utilizzata, nei casi in cui vi sia una notevole perdita di tessuto cutaneo, è il trapianto di cute autologa. Tale metodica, pur consentendo di ripristinare la barriera cutanea danneggiata, presenta alcuni problemi quali la frequente assenza o scarsità di zone donatrici, la suscettibilità alle infezioni delle superfici così trattate e la creazione di ulteriori esiti cicatriziali a livello delle aree di prelievo. 


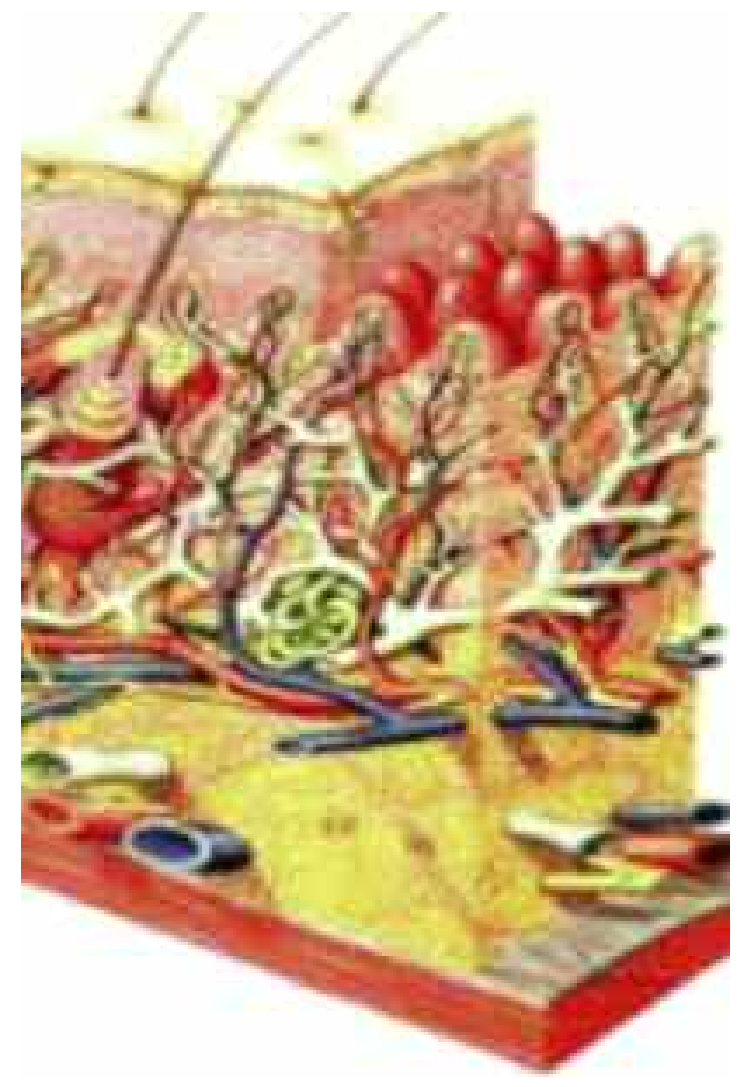

Fig. 4.

Il disegno qui a fianco rappresenta la struttura della cute, formata da epidermide e derma. La parte più superficiale è l'epidermide. Sotto l'epidermide si sviluppa il derma all'interno dei quali troviamo immersi $i$ vasi, le terminazioni nervose ed i bulbi piliferi. La cute infine poggia sul pannicolo adiposo e quindi sulle fasce muscolari qui rappresentate in rosso sul fondo della figura.

Pertanto, in assenza di sufficiente cute autologa, nel caso di grandi ustionati, o di notevole perdita cutanea, di norma si procedeva ad una ricostruzione dermica mediante cute allologa, generalmente proveniente da cadavere, sulla quale veniva applicato un'innesto di cute autologa ultrasottile, eventualmente espansa mediante estensore a meshgraft. Tuttavia neanche questo rappresenta un trattamento ottimale, in quanto, spesso, il centro non dispone di una banca di tessuti e, nel caso di un'ustione estesa, il soggetto non presenta sufficienti aree donatrici.

Il trattamento d'elezione in questi casi è il ricorso a cute allologa totale $\mathrm{o}$, in taluni casi, a cute xenogenica. Tuttavia l'esperienza clinica degli ultimi vent'anni ha chiaramente dimostrato che anche questa soluzione è comunque gravata da forti limitazioni, principalmente di ordine infettivologico. 
Anche le ulcere croniche rappresentano un notevole problema. Infatti, benché in questi casi l'area della lesione non sia generalmente così ampia, i trattamenti tradizionali sono talvolta destinati al fallimento, per motivi non sempre noti. Ad esempio, nel caso delle ulcere venose, non è chiaro quale sia il meccanismo che impedisce la migrazione dell'epitelio, come pure il non attecchimento di un innesto cutaneo autologo.

Il progresso tecnologico nel settore dei biomateriali ha rivoluzionato in pochi anni le tecniche di trattamento delle ferite. Infatti per decenni l'unico materiale disponibile era rappresentato dalla garza di lino o di cotone, che spesso però produceva traumi secondari al momento della rimozione, con sanguinamento ed asportazione del neo-epitelio. Le garze venivano quindi impregnate di paraffina al fine di renderle meno aderenti. L'evoluzione del concetto di guarigione delle ferite ha portato alla definizione di nuovi prodotti che fossero in grado non solo di coprire la ferita, ma anche di interagire con essa, rispettando ad esempio l'omeostasi dell'ambiente tessutale in fase di riorganizzazione, ed emulando alcune proprietà della cute lesa, prima fra tutte la capacità di barriera unita alla traspirazione. L'ulteriore sviluppo di questi concetti ha portato alla creazione in vitro di tessuti veri e propri (epidermide), oppure di componenti strutturali fondamentali (e.g. dermi artificiali, colture di fibroblasti dermici).

Nel tentativo di superare i problemi posti dalle lesioni del mantello cutaneo, l'ingegneria tessutale ha utilizzato diverse strategie volte a stimolare la guarigione della lesione attraverso i normali meccanismi biologici di rigenerazione e riparazione tessutale. Tali strategie sono essenzialmente riconducibili a due tipologie di approccio che prevedono: i) l'impiego di sostituti cutanei naturali o semi-artificiali acellulari, quali, ad esempio, la cute di cadavere trattata e collageno animale, o matrici tridimensionali a base di polimeri semisintetici, quali, ad esempio, il collageno cross-linkato e i derivati dell'acido ialuronico. Essi fungono da scaffold, vengono cioè colonizzati dalle cellule dell'ospite offrendo loro un reticolo tridimensionale sul quale iniziare la deposizione di matrice extracellulare, ripristinando il tessuto mancante. Nel contempo lo scaffold, a seconda della sua composizione, si riassorbe o si reintegra nel neo-tessuto. ii) L'utilizzo di sostituti cutanei con componente cellulare allologa o autologa. In questi casi il tessuto mancante sarà ricostruito in vitro e poi innestato. A tale scopo sono stati messi a punto diversi tipi di sostituti cutanei: sostituti epidermici, dermici e sistemi misti, basati rispettivamente su colture di cheratinociti, fibroblasti, e co-colture di 
cheratinociti e fibroblasti che sono appunto rispettivamente le cellule principali di epidermide e derma (Fig. 4).

Un importante sviluppo si è avuto grazie alla ricerca di polimeri "intelligenti" che fungessero da scaffold per i prodotti del tissue engineering e fossero in grado di modulare le loro caratteristiche chimico-fisiche in funzione del livello di integrazione tessutale raggiunto dal costrutto ingegnerizzato. Si era infatti osservato che alcuni derivati dell'acido ialuronico(HYAFF ${ }^{\circledR}$, esteri benzilici dell'acido ialuronico) erano dotati di una spiccata biocompatibilità in vitro ed in vivo (Campoccia et al, 1998).

I primi prodotti sviluppati per la guarigione delle ferite venivano inclusi nell'ambito delle cosiddette "medicazioni avanzate", in quanto la progressiva dissoluzione del prodotto nel letto della ferita liberava acido ialuronico, che era in grado di riattivare il processo di guarigione. Nel contempo la dissoluzione del materiale rendeva le eventuali successive medicazioni assolutamente non traumatiche.

Nel corso dello studio dei polimeri $\mathrm{HYAFF}^{\circledR}$ ci si rese conto che, oltre alla loro notevole biocompatibilità, essi possedevano altre caratteristiche che li rendevano adatti a fungere da scaffold per costrutti bioingegnerizzati. In particolare è stato dimostrato che i prodotti di degradazione dello $\mathrm{HYAFF}^{\circledR}$ (oligomeri dell'acido ialuronico) posseggono proprietà angiogenetiche (West, 1985) che quindi favoriscono ulteriormente il processo di integrazione del tessuto ingegnerizzato

È interessante notare come la ricerca finalizzata alla messa a punto di biomateriali intelligenti da utilizzare quali scaffold ideali per l'ingegneria tessutale, abbia poi portato all'identificazione di sistemi avanzati di medicazione delle ferite e di tissue augmentation, anche in virtù delle caratteristiche intrinseche dei materiali (e.g. porosità, degradabilità, integrazione, drug release system).

\section{SOSTITUTI EPIDERMICI}

Nel tentativo di superare i principali limiti della tecnica tradizionale basata sulla tecnologia ideata da Rheinwald e Green (Rheinwald e Green, 1975), a fine degli anni '80 il connubio tutto italiano fra ricerca ed industria ha portato alla messa a punto di una membrana microperforata a base di un derivato estereo dell'acido ialuronico (HYAFF ${ }^{\circledR}$ ) che ha rappresentato il primo supporto su cui far sviluppare le colture di cheratinociti (Andreassi et al, 1991) (Fig. 5). 
Le tecniche della ingegneria dei tessuti possono infatti risultare estremamente utili nel caso di grandi ustionati o di lesioni cutanee molto estese, in cui è essenziale ripristinare, nel minor tempo possibile, l'integrità dell'epidermide (Harris et al, 1998).

La membrana è estremamente sottile (lo spessore è di circa 20 $\mu \mathrm{m})$, trasparente, presenta una buona adesività per le cellule, è dotata di microperforazioni (diametro di $40 \mu \mathrm{m}, 6.250$ perforazioni $/ \mathrm{cm}^{2}$ ) prodotte mediante laser, e di fori di diametro più grande $(0,5 \mathrm{~mm})$ che intervallano le serie di microperforazioni. La trasparenza ottica della membrana permette di controllare la coltivazione del tessuto al microscopio, mentre la membrana, adesa, ma non stabilmente connessa alla superficie del contenitore, può essere facilmente sollevata a fine coltura e trasferita nei contenitori di trasporto: la membrana, cioè, sostiene e protegge le cellule epiteliali dalle sollecitazioni meccaniche connesse al trasporto e alla manipolazione del costrutto.
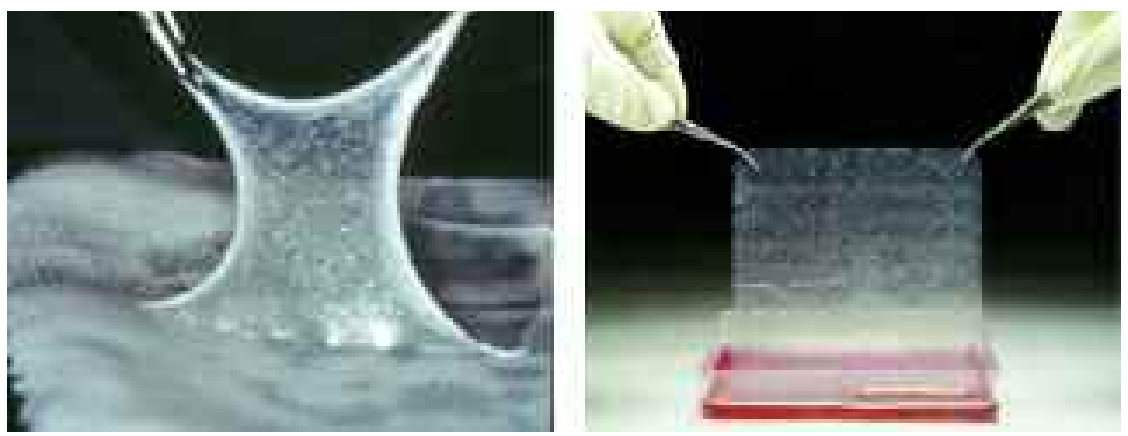

Fig. 5.

Nel pannello di sinistra la classica coltura epidermica a seguito dell'applicazione della tecnica scoperta da Rheinwald e Green; a destra invece è la fotografia della membrana microperforata di HYAFF® (Laserskin $®$ ). E facilmente apprezzabile il vantaggio di uno scaffold tridimensionale in questo tipo di applicazione.

La sua caratteristica peculiare è costituita dalle microperforazioni attraverso le quali le cellule epiteliali migrano dalla faccia superiore a quella inferiore, ovvero dalla membrana al letto sottostante della ferita, una volta che la membrana sia stata posizionata su di esso. Si formano così, in corrispondenza delle perforazioni, migliaia di "isole epiteliali", che accelerano il processo di attecchimento. L'eventuale essudato in eccesso viene allontanato attraverso le perforazioni più grandi, regolarmente collocate sulla membrana. 
L'utilizzo di uno scaffold tridimensionale ha rappresentato un notevole passo in avanti verso una maggiore disponibilità di epidermide autologa ingegnerizzzata, in quanto permette l'innesto di un costrutto cellulare dalle migliori caratteristiche fisiologiche e meccaniche migliorando al contempo la modalità di applicazione chirurgica che risulta molto più semplice e veloce.

A questo si aggiunge l'accorciamento dei tempi di coltivazione in vitro. Infatti, grazie alla membrana, che funge da supporto, è possibile fornire colture di cheratinociti pre-confluenti, ovvero non ancora stratificati ed in fase di attiva proliferazione e migrazione all'interno delle microperforazioni, con un recupero dei tempi medi di produzione dei costrutti di circa il $50 \%$.

\section{SOSTITUTI DERMICI}

Come è già stato accennato, uno dei problemi fondamentali, nel caso di gravi ustioni o perdite estese di sostanza, risiede nel ripristino della componente dermica, al fine di assicurare un recupero funzionale ed estetico accettabile e di ottenere un miglior attecchimento dell'epidermide ingegnerizzata. Sono stati sviluppati diversi prodotti il cui denominatore comune è la tridimensionalità degli scaffold.

È opportuno ricordare che l'acido ialuronico (HA) è un polisaccaride altamente conservato nella storia evolutiva ed è ampiamente distribuito nel corpo umano (Fig. 1). Tali caratteristiche rendono la molecola dell'HA priva di immunogenicità, facilmente assimilabile e quindi completamente sicura. A livello del tessuto cutaneo, l'HA svolge un ruolo importante sia in normali condizioni fisiologiche, sia durante i processi riparativi. Infatti, l'HA favorisce l'idratazione tessutale ed influenza diverse attività cellulari, fra cui la migrazione e la proliferazione di cheratinociti e fibroblasti. Esso è inoltre in grado di influenzare la deposizione ordinata delle fibre di collageno prodotte dai fibroblasti del derma: pertanto la sua presenza favorisce una guarigione con minori esiti cicatriziali. Queste attività biologiche sono possibili in quanto molte cellule possiedono dei recettori di superficie, grazie ai quali possono riconoscere e legarsi all'acido ialuronico (Chen e Abatangelo, 1999).

Basandosi su queste premesse è stato sviluppato un prodotto composto da due strati: uno strato, destinato al contatto con la ferita, costituito da un riquadro di tessuto non-tessuto assorbente e biodegradabile intera- 
mente a base di $\mathrm{HYAFF}^{\circledR}$, ed un altro composto da una pellicola trasparente e flessibile di elastomero sintetico che agisce da barriera semipermeabile agli agenti esterni. Non appena la matrice viene a contatto con il siero o l'essudato della ferita, lo strato di non-tessuto assorbe l'acqua, trasformandosi in un gel idrofilo che provvede a costituire un microambiente favorevole alla ricostruzione ordinata del tessuto dermico. La pellicola trasparente di elastomero, grazie alla capacità di trasmissione del vapore paragonabile a quella della cute integra, evita un'eccessiva perdita di fluidi corporei, mentre la trasparenza della pellicola, consente un continuo monitoraggio della ferita senza richiederne la rimozione. Questo scaffold è indicato in tutte quelle situazioni in cui sia necessario ripristinare, parzialmente o totalmente, lo strato dermico (a seguito di escissioni chirurgiche, ustioni profonde e perdite di sostanza conseguenti a traumatismi). Il suo meccanismo d'azione è peculiare e fondamentalmente diverso dagli altri sostituti dermici acellulari. In questo caso la rigenerazione dermica viene stimolata dall'apporto di quantità notevoli di acido ialuronico che derivano dalla degradazione spontanea dell'estere nell'ambiente della ferita. Infatti, in seguito alla degradazione delle fibre di $\mathrm{HYAFF}^{\circledR}$ si ha il rilascio di alcol benzilico (sostanza comunemente utilizzata come conservante nelle preparazioni farmaceutiche per uso parenterale e di cui è completamente noto il pattern metabolico) e di acido ialuronico.

\section{Sostituti dermici con componente cellulare}

Come già detto, i sostituti dermici prevedono un substrato su cui far sviluppare la componente cellulare costituita da fibroblasti di origine allogenica o autologa. Nel primo caso (fibroblasti allogenici) il vantaggio fondamentale risiede nella immediata disponibilità del prodotto mentre nel secondo caso si devono considerare i tempi di produzione del costrutto autologo.

Inoltre, nel caso dei prodotti allologhi si è visto che non insorgono risposte anticorpali o di rigetto acute, probabilmente perché nel corso del processo di coltivazione in vitro gli antigeni di istocompatibilità di classe I vengono repressi e quindi viene a mancare lo stimolo principale al rigetto acuto. Tuttavia la presenza di antigeni minori, e l'eventuale nuova espressione degli antigeni maggiori a seguito dell'impianto, fanno sì che i costrutti allologhi non si integrino stabilmente nel tessuto dell'ospite e vengano quindi eliminati in tempi relativamente brevi 
(circa 20-30 giorni). I costrutti autologhi non presentano tali problemi, però necessitano di tempi di produzione più lunghi rispetto ai costrutti allogenici, e devono essere programmati sia per quanto riguarda il prelievo bioptico, sia per quanto riguarda l'innesto.

\section{Sostituti dermici autologhi}

L'unico sostituto dermico autologo attualmente presente sul mercato è com,posto da uno scaffold tridimensionale a base di acido ialuronico totalmente esterificato (Fig. 6). All'interno di questa matrice vengono seminati i fibroblasti autologhi, ricavati da una piccola biopsia cutanea del paziente stesso e coltivati per circa due settimane prima della semina sul substrato (Fig. 3). Relativamente alla componente cellulare, i prodotti allologhi ed autologhi non sono molto diversi, se non per un superiore tasso di proliferazione cellulare (e quindi, probabilmente, di sintesi proteica) mostrato dalle cellule neonatali rispetto ai fibroblasti dermici adulti.
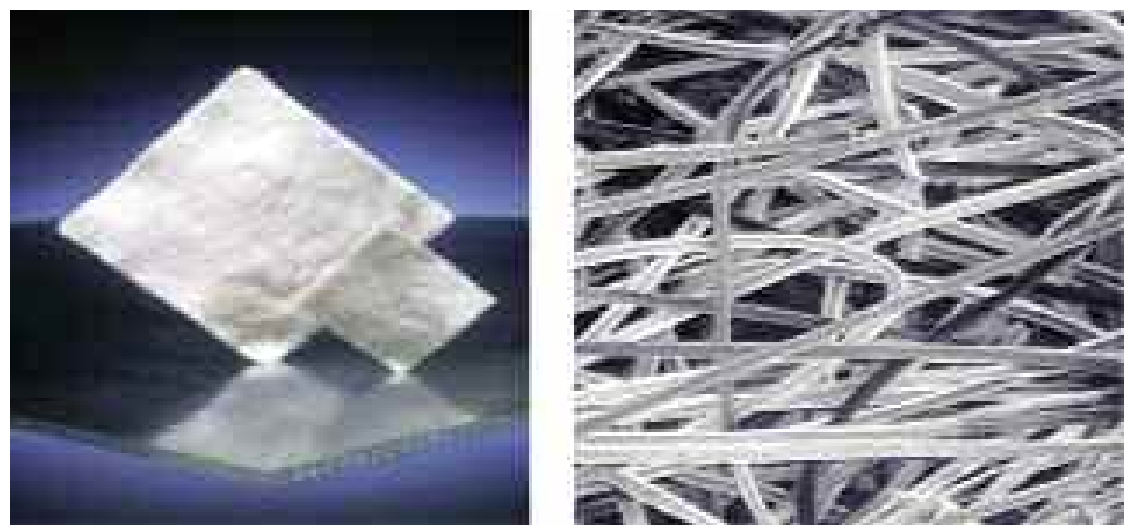

Fig. 6.

La fotografia di sinistra mostra Hyalograft $3 D^{\mathrm{TM}}$. Questo scaffold è composto da HYAFF ${ }^{\circledR}$ totalmente esterificato in forma di tessuto-non tessuto.

La microfotografia di destra mostra la struttura delle micro-fibre del biomateriale disposte in modo casuale a formare la matrice. Questa particolare configurazione consente di mimare l'organizzazione delle fibre di collageno della matrice extracellulare.

La degradazione dello scaffold in oligomeri a basso peso determina il fenomeno

della neo-angiogenesi, favorendo quindi il processo di integrazione del costrutto al sito di impianto (vedi testo). Hyalograft $3 D^{\mathrm{TM}}$ fa parte di un sistema di ricostruzione dermo-epidermica autologa, in associazione a Laserskin ${ }^{\circledR}$. 
D'altro canto, però, solo nel caso di prodotti autologhi avviene un'effettiva integrazione nel letto della ferita. Conseguentemente, i prodotti autologhi sono da preferire rispetto ai costrutti allologhi, pur necessitando di un processo produttivo più complesso.

\section{SOSTITUTI DERMO-EPIDERMICI}

Negli ultimi anni è emersa la possibilità di avere la ricostruzione sia del derma che dell'epiderma. Per realizzare questa possibilità è stata sviluppata un'ulteriore tipologia di prodotti che prevede la ricostruzione in vitro di un sostituto a due componenti, epidermica e dermica, la cui fonte cellulare può essere di derivazione allologa o autologa.

\section{Sostituti dermo-epidermici autologhi}

Le cellule impiegate (cheratinociti e fibroblasti) provengono da una piccola biopsia prelevata dal paziente stesso, per cui sono eliminati i problemi di rigetto e sicurezza della fonte cellulare. Questo è un processo suddiviso in due fasi: all'applicazione del sostituto dermico fa seguito, dopo 7-10 giorni (tempo necessario per avere un attecchimento del sostituto dermico) l'innesto del sostituto epidermico (Fig. 3). Gli scaffold a base di $\mathrm{HYAFF}^{\circledR}$ utilizzate nelle due fasi sono state specificamente progettate per mimare in vitro l'architettura del tessuto di riferimento.

Impiegando cellule autologhe, che quindi possiedono una maggiore probabilità di attecchimento, non sono generalmente necessarie applicazioni ripetute, come avviene invece per i sostituti cutanei allologhi. Relativamente alle ulcere del piede diabetico, l'efficacia di questa tecnologia è stata dimostrata, in particolare, in un recente studio clinico multicentrico controllato e randomizzato (Caravaggi et al., 2003).

Un altro dato di estrema importanza emerge da un'analisi osservazionale retrospettiva: su un totale di 367 pazienti trattati il tasso di recidivazione delle ulcere da piede diabetico è meno di un terzo rispetto ai trattamenti standard riportati in letteratura (Uccioli et al., 2003). È stato inoltre evidenziato che questa tecnologia come del resto anche gli altri costrutti cellularizzati sopra descritti, ha un effetto lenitivo sul dolore, aspetto questo di grande importanza soprattutto nelle ulcere con componente ischemica, generalmente molto dolorose. 


\section{Cartilagine articolare ingegnerizzata}

La cartilagine articolare è un tessuto elastico dotato di notevole resistenza alla pressione e alla trazione. La sua funzione è simile a quella di un cuscinetto ammortizzatore che con la sua azione salvaguardia i normali rapporti articolari e permette il movimento. Queste importanti caratteristiche sono permesse dalla sua particolare costituzione chimica. All'interno della cartilagine esistono infatti delle cellule, chiamate condrociti, che hanno il compito di produrre la sostanza fondamentale. Tale sostanza è costituita prevalentemente da acqua, da fibre collageniche, da proteoglicani, da acido ialuronico e da glicoproteine (Fig. 7). Il tessuto cartilagineo non essendo vascolarizzato riceve il nutrimento tramite il fenomeno della diffusione, un processo lento e molto meno efficace della circolazione sanguigna. Per tutti questi motivi le capacità rigenerative di questo tessuto sono bassissime.
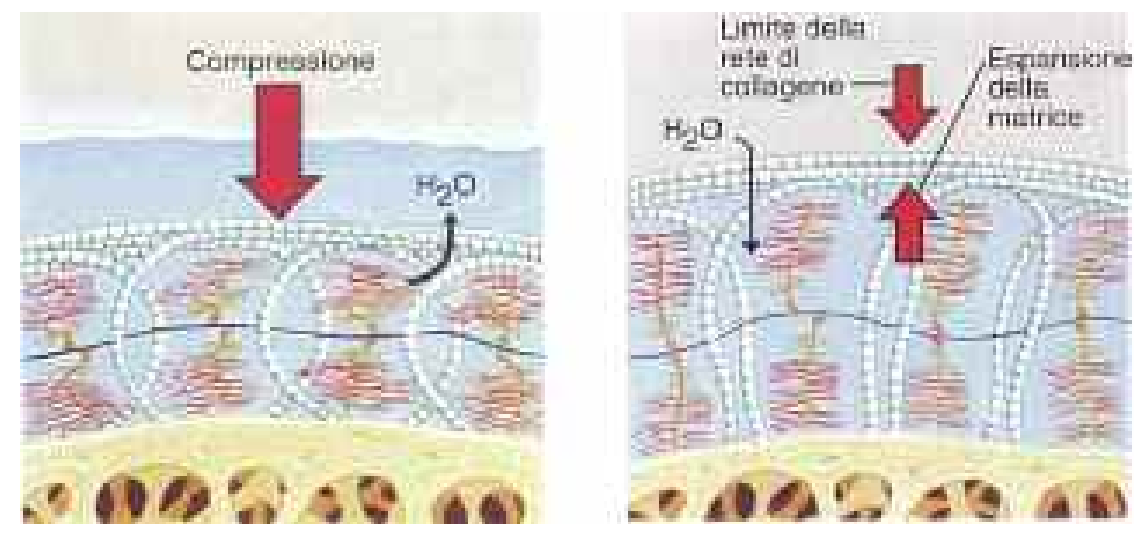

Fig. 7.

La funzione meccanica della cartilagine articolare. I glicosaminoglicani regolano l'idratazione della cartilagine e la capacità di resistere alle compressioni.

La cartilagine ialina conferisce alle estremità articolari delle ossa una superficie liscia che permette il movimento dell'articolazione in modo virtualmente privo d'attrito. Le lesioni della cartilagine articolare rappresentano una patologia molto diffusa che affligge milioni di persone nel mondo. Tali lesioni possono essere di tipo traumatico, spesso dovute all'attività sportiva, o degenerativo, causate dall'osteocondrite disseccante. 
Oggi si ritiene che, con la progressione di tale lesioni, il soggetto divenga predisposto all'artrosi con l'eventuale necessità di un impianto protesico nel caso non siano più sopporta bili il dolore e le limitazioni all'attività fisica che una simile patologia inevitabilmente comporta. Nelle fasi iniziali, tali lesioni sono frequentemente asintomatiche, in quanto la cartilagine manca di innervazione e vascolarizzazione proprie. Di conseguenza i soggetti non avranno percezione del danno fintanto che la degenerazione tessutale non avrà raggiunto l'osso sottocondrale, nel qual caso i sintomi avvertiti saranno quelli tipici di una lesione meniscale. Infatti, i pazienti accusano, in questi casi, dolore e gonfiore al ginocchio, rigidità articolare e cedimenti dell'articolazione. L'impossibilità di rigenerazione a livello della cartilagine articolare risiede probabilmente nell'assenza di vascolarizzazione del tessuto, e quindi nell'impossibilità di attivare un processo infiammatorio di riparazione tessutale (Peterson, 1996).

\section{LIMITI DEI TRATTAMENTI CONSERVATIVI TRADIZIONALI}

Le varie tecniche tradizionali (shaving e infiltrazioni, mosaicoplastica, microfratture e perforazioni osteocondrali, ecc.) non sono in grado di riprodurre una cartilagine di tipo ialino, non consentendo quindi l'uso funzionale dell'articolazione. Tali rimedi alleviano il dolore o mobilizzano l'articolazione nel breve-medio periodo, successivamente però il problema si ripropone, spesso in modo aggravato (Fig. 8). Alcune di esse (stimolazione osteocondrale, microfratture, ecc.) conducono alla formazione di fibrocartilagine, un tessuto di riparazione dalle caratteristiche meccanico-elastiche sensibilmente inferiori alla cartilagine ialina.

Infatti tale tessuto degenera in un arco temporale relativamente breve. Conseguentemente, il soggetto viene sottoposto ad interventi di ricostruzione via via più impegnativi, sino a dover ricorrere, nei casi estremi, a protesi artificiali mono o bi-compartimentate, quindi con interventi piuttosto aggressivi.

I limiti intrinseci della rigenerazione di un tessuto ialino sono imputabili principalmente alle caratteristiche fisiologiche del tessuto stesso. All'osservazione diretta, la cartilagine ialina appare come una superficie bianca, liscia, omogenea e ben lubrificata, priva di innervazione e vascolarizzazione. Le superfici articolari combacianti sono talmente lubrificate da presentare un coefficiente di frizione inferiore a quello del ghiaccio su ghiaccio. 


\section{$\checkmark$ Lavaggio, turettage, debridement

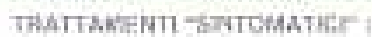

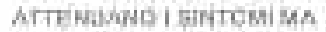

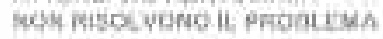 \\ - Porforazioni subcandrali, microlratture

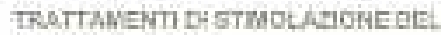 MIDOLLO OSEEO : HISUTATI POCD PFIEVEHEQ⿻

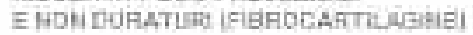

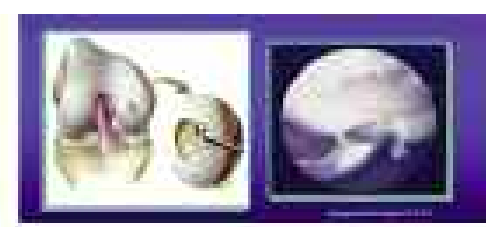

\section{Autotrapiant osteocondrafi}

TACSEUCDPLASTICA

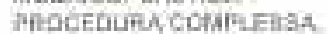

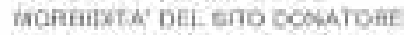

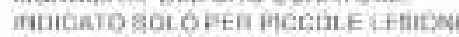
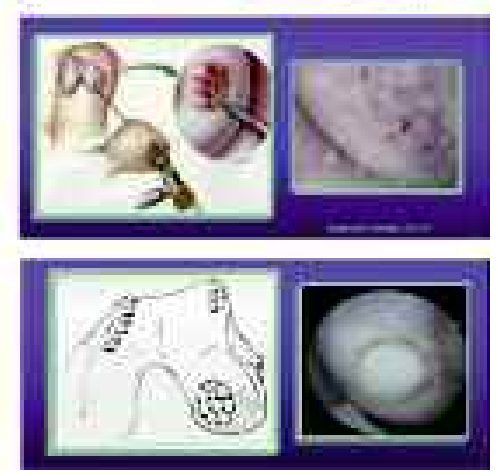

Fig. 8 .

Le tecniche tradizionali. Tecniche chirurgiche conservative per la riparazione dei difetti alla cartilagine articolare.

Nonostante l'apparenza, l'organizzazione strutturale del tessuto è molto complessa e ha la funzione, come detto, di minimizzare lo sforzo ed il carico sull'osso subcondrale, e l'attrito a livello dell'articolazione sinoviale. La cartilagine articolare è costituita da una matrice gelificata contenente fibre di collageno di tipo II e glicosaminoglicano (Fig. 7). Queste macromolecole della matrice, sintetizzate dai condrociti stessi, e la caratteristica distribuzione delle fibre di collageno, colonnare nella zona più profonda e tangenziale nella zona superficiale, sono i principali fattori che determinano le proprietà meccaniche e funzionali del tessuto. Lo strato più esterno (la zona superficiale) è costituita da una superficie liscia e sottile, con alto contenuto di collageno e basso contenuto di proteoglicani. Lo strato successivo (zona di transizione) contiene fibrille di collageno più grosse, con un contenuto maggiore di proteoglicani; infine la zona profonda ha il massimo contenuto in proteoglicani ed il minimo contenuto in acqua (per una review sull'argomento si veda Buckwalter, 1990). Una volta che questa complessa architettura si è sviluppata, $i$ condrociti, immersi nella matrice, si dividono raramente; il loro numero e le relative capacità rigenerative diminuiscono lentamente con l'avanzare dell'età. Tutto ciò contribuisce a limitare notevolmente le capacità di riparazione spontanea di questo tessuto. 
Lesioni cartilagine e a spessore parziale, che cioè non si estendono fino all'osso subcondrale e quindi non sono a diretto contatto con i vasi del midollo osseo, hanno minime, o nulle, capacità di autoriparazione; mentre lesioni a tutto spessore, in cui cioè vi è l'interessamento della zona più superficiale dell'osso subcondrale, possono portare a una parziale rigenerazione in quanto si assiste ad una migrazione dei progenitori staminali dal midollo e ad un principio di vascolarizzazione. Tuttavia questo tessuto di riparazione è costituito da fibrocartilagine, prevalentemente contenente collageno di tipo I e dotato di scarse qualità meccaniche. Col tempo, come già detto, il tessuto fibrocartilagineo tende a deteriorarsi, pertanto il processo di riparazione spontanea di simili lesioni non potrà mai ripristinare un tessuto funzionalmente simile al preesistente, ma tenderà ad esitare nell'artrosi, a causa dell'attrito e del carico eccessivo ai capi articolari opposti, con usura e degenerazione degli stessi (Buckwalter e Mankin, 1997).

\section{L'INGEGNERIA TESSUTALE DELLA CARTILAGINE}

L'obiettivo ultimo della terapia delle lesioni cartilaginee è ovviamente quello di restituire al soggetto la piena capacità di mobilizzare l'articolazione senza accusare dolore, prevenendo l'ulteriore degenerazione tessutale. Ciò può essere perseguito sia trattando il sintomo (dolore), sia instaurando un processo di reale rigenerazione della cartilagine ialina. L'attenzione si è da subito focalizzata sul ginocchio, in quanto questa è un'articolazione assai fragile, con un elavato numero di interventi/anno ed è infine facilmente aggredibile dal punto di vista chirurgico.

I primi tentativi in questo senso miravano a ricostruire la cartilagine ialina del ginocchio mediante l'innesto di periocondrio, ricavato dalla cartilagine costale del paziente, oppure di periostio, posizionando il lato cambiale (ricco di precursori staminali indifferenziati) verso l'articolazione.

Tuttavia, solo gli esperimenti su animali avevano dato risultati positivi, mentre i primi dati clinici non erano confortanti, in quanto dopo un'iniziale ripristino della funzionalità articolare con neo-formazione di cartilagine simil-ialina, nel lungo periodo, si riscontrava un processo di ossificazione endocondrale con delaminazione dello strato cartilagine o neo-formato.

Nonostante questi insuccessi iniziali, si dimostrava che alcuni tessuti (pericondrio, periostio) contenevano cellule progenitrici in grado di 
differenziare in fenotipi più specializzati, se poste nelle condizioni appropriate, in questo caso l'ambiente articolare (Minas e Nehrer, 1997).

Nelle successive ricerche venivano studiate fonti cellulari alternative. In particolare l'attenzione veniva focalizzata sui condrociti stessi, cioè sulle cellule costituenti il tessuto da rigenerare, le quali erano sicuramente meno soggette a differenziamenti non fisiologici. Alla fine degli anni '70 le tecniche di coltura erano perfezionate al punto da poter coltivare in vitro condrociti isolati da biopsie cartilaginee. Si era infatti in presenza di un paradosso biologico: nonostante il tasso quasi nullo di replicazione in vivo, $\mathrm{i}$ condrociti articolari proliferavano in vitro andando incontro al cosiddetto fenomeno della de-diffenziazione, ovvero la perdita del loro fenotipo caratteristico, con assunzione di morfologia e comportamento fibroblastoide. Gli esperimenti di ri-differenziazione dimostravano che, in appropriate condizioni colturali, era possibile revertire tali cellule al loro fenotipo originario, con riacquisizione dei tratti condrocitari caratteristici, primo fra tutti la rinnovata produzione di matrice extracellulare contenente quantità elevate di aggrecano e collageno di tipo II.

Gli esperimenti su animali dimostravano che in lesioni cartilaginee a tutto spessore si otteneva una rigenerazione cartilaginea completa a seguito di innesto di condrociti autologhi (de-differenziati) coltivati in vitro. Per arrivare a questo risultato si era dovuto sviluppare una tecnica operatoria semplice ma laboriosa: poiché si somministrava una sospensione cellulare, bisognava far sì che la sospensione stessa rimanesse confinata al sito di impianto. Ciò si otteneva mediante un flap periostale, in altre parole si prelevava una porzione di periostio dall'osso tibiale dell'animale e lo si suturava ai margini sani del difetto cartilagineo (lato cambiale sul versante interno) in modo che formasse una camera stagna entro la quale veniva infine iniettata la sospensione cellulare.

I risultati radiografici ed istologici dimostravano che in oltre 1' $80 \%$ delle lesioni trattate con condrociti coltivati in vitro si rigenerava cartilagine ialina (Grande, 1989).

\section{La tecnica ACI (Autologous Chondrocyte Implantation)}

Sulla base dei risultati esaminati al punto precedente, nel 1987 un gruppo svedese, guidato da Peterson, Brittberg e Lindhal, decideva di applicare la succitata tecnica, denominata ACI (Autologous Chondrocyte Implantation) in un gruppo selezionato di pazienti. 
La procedura è suddivisa in due tempi: la prima fase prevede un prelievo in artroscopia dall'articolazione interessata di una piccola biopsia cartilaginea del peso di circa $200-300 \mathrm{mg}$. La zona di prelievo viene scelta tra quelle non soggette a carico (in genere il condilo femorale mediale superiore) e deve ovviamente essere composta da tessuto sano. La biopsia, conservata in un appropriato terreno nutrizionale, viene inviata al centro di trattamento, dove i condrociti vengono dissociati dalla matrice mediante digestioni enzimatiche, e quindi posti in coltura. Inizia così il processo di de-differenziazione, durante il quale i condrociti originali perdono i loro tratti morfologici caratteristici ed iniziano a replicarsi espandendo rapidamente la popolazione iniziale. È pertanto possibile concludere che nel lungo termine i risultati sono molto soddisfacenti, essendo stato possibile rigenerare cartilagine ialina in un numero molto significativo di casi. A seguito dei lusinghieri successi ottenuti con la tecnica svedese questa innovativa terapia è stata portata sul mercato americano (Fig. 9).

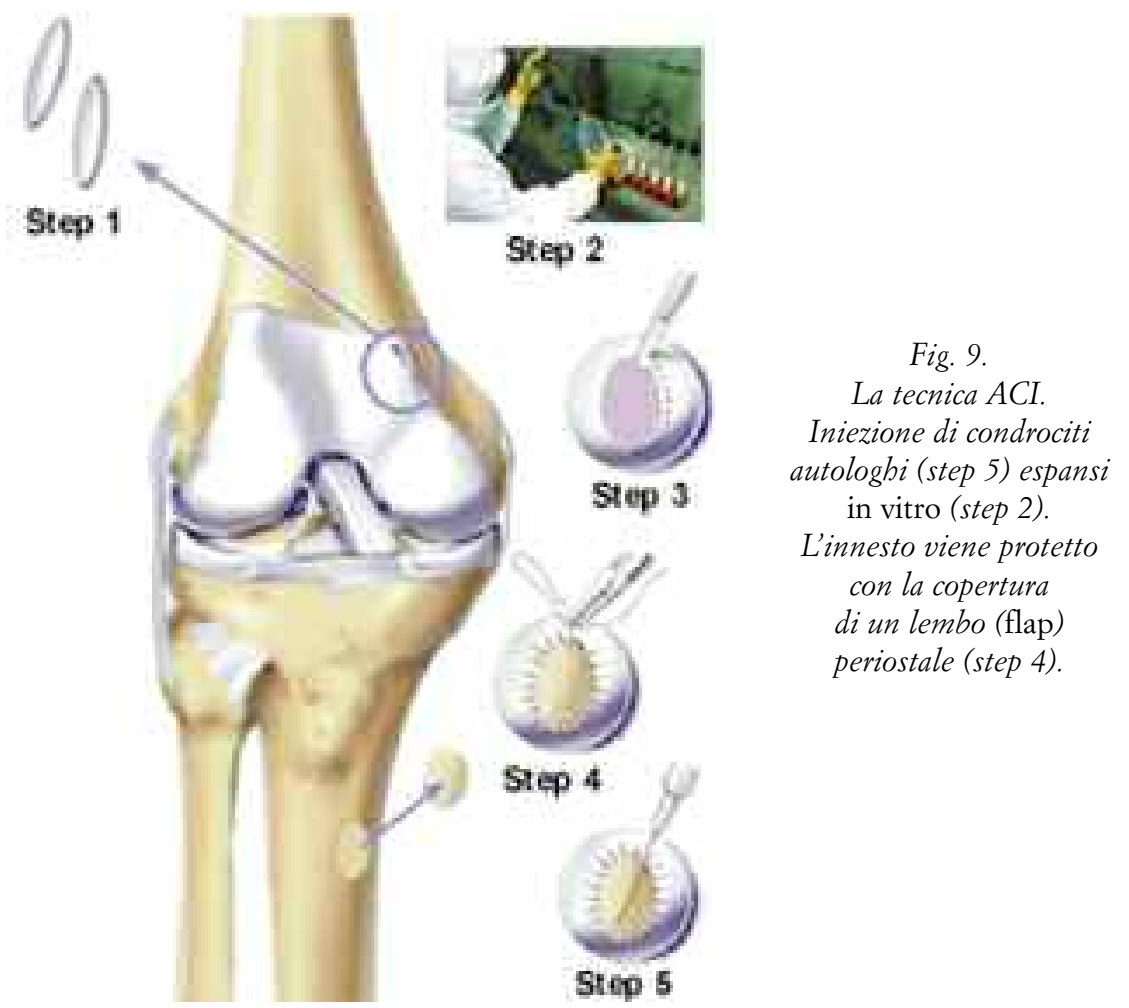




\section{Limiti della tecnica ACI}

Con il consolidamento della tecnica ACI ne sono emersi anche i suoi limiti che sono dovuti essenzialmente al sistema di coltura e alla tecnica operatoria.

Nel primo caso l'impiego di siero autologo comporta una maggiore complessità del flusso produttivo, in quanto per ogni linea cellulare si devono allestire terreni di coltura specifici. Inoltre esiste una variabilità delle caratteristiche del siero autologo, legata ad esempio alle condizioni di trasporto del sangue, alle condizioni in cui il prelievo è stato effettuato (il siero da pazienti non a digiuno o dopo assunzione di anestetici a base di oppiacei registra tassi di proliferazione cellulare più bassi) $\mathrm{o}$, più semplicemente, dovuta a variabilità individuale. L'impiegò di siero fetale bovino (FCS) permette invece di avere condizioni di coltura maggiormente controllate ed è possibile, attraverso definite procedure di screening, selezionare un lotto di siero dalle caratteristiche ottimali e utilizzare tale lotto nel corso di molte lavorazioni. I tipi di FCS utilizzati devono provenire da fornitori certificati, e devono essere autorizzati per l'impiego nella produzione di sostanze medicinali, come vaccini e anticorpi destinati all'utilizzo clinico. Un ulteriore limite della tecnica di coltura risiede nell'assenza di una matrice tridimensionale opportuna da utilizzare quale delivery system, ma questo punto verrà affrontato specificamente più avanti.

I limiti relativi alla tecnica operatoria derivano dalla necessità di recuperare il flap periostale, operazione di per sé lunga e laboriosa, ma che soprattutto impedisce il ricorso a tecniche meno invasive quali la miniartrotomia o tecniche artroscopiche. Il flap periostale è inoltre responsabile di una complicazione che ricorre in circa il 10-15\% dei casi: l'ipertrofia del periostio, con conseguente laminazione, presenza di corpi estranei nel liquido sinoviale e dolore articolare. In tali casi è necessario un intervento di revisione, condotto per via artroscopica, mirato alla rimozione del tessuto esuberante: ciò non preclude l'efficacia della terapia, ma ne aumenta i costi globali a causa del re-intervento (Minas e Peterson, 1999).

In considerazione dei limiti suesposti, sono state studiate nuove soluzioni tra le quali l'utilizzo di una matrice a base di acido ialuronico quale supporto per l'innesto di condrociti autologhi nel sito della lesione articolare. 


\section{Colture di condrociti su scaffold a base di HYAFF“}

La tecnica ACI presenta uno svantaggio fondamentale: l'assenza di un substrato entro il quale far proliferare le cellule condrocitarie dedifferenziate. La presenza di tale substrato si rende necessario per una duplice motivazione: i) le cellule di un tessuto sono disposte all'interno di una struttura tridimensionale, si suppone quindi che una simile distribuzione spaziale sia ottimale anche nel caso di costrutti cellulari ingegnerizzati; ii) un costrutto tridimensionale viene collocato in sede e vi rimane più facilmente di una sospensione cellulare.

Per quanto riguarda il primo punto, è ben noto che i condrociti che in coltura de-differenziano, acquisiscono nuovamente il fenotipo originale mediante semina ad alta densità o adesione a substrati tridimensionali (la densità di semina è comunque sempre un parametro critico). I condrociti in via di differenziazione producono quei precursori della matrice extracellulare (ECM) necessari alla formazione della cartilagine ialina (glisosaminoglicani, aggrecano, collageno di tipo II). La presenza di tali precursori favorirà l'integrazione del costrutto al sito di innesto. Numerosi sono i biomateriali proposti quali scaffold di condrociti, ma solo due sono attualmente impiegati su larga scala: il collageno di tipo I/III e l'acido ialuronico derivatizzato. Anche in questo caso, come per la pelle, l'industria italiana ha sviluppato dei prodotti innovativi basandosi sui principi della ingegneria dei tessuti. Cosa poi molto importante ha ottenuto la certificazione da parte delle autorità competenti necessaria al loro utilizzo nei pazienti. Per quanto riguarda la cartilagine, di particolare interesse risulta una matrice tridimensionale biodegradabile in forma di tessuto-non tessuto, in grado di essere colonizzata dai condrociti, i quali già nella fase di coltivazione in vitro all'interno della matrice iniziano il processo di re-differenziazione, e si organizzano in modo da formare un tessuto simil-cartilagineo. È stato dimostrato infatti che i principali marcatori tessutali della cartilagine ialina (collageno II e aggrecano) vengono espressi nuovamente (Grigolo, 2002).

Il chirurgo si trova così ad innestare non più una sospensione cellulare, ma un tessuto cartilagineo parzialmente ricostruito in vitro, che si integrerà facilmente a livello del sito di impianto. L'integrazione del tessuto ingegnerizzato è inoltre favorita dalla spontanea degradazione dello scaffold (in circa tre mesi la matrice è completamente degradata), che porta alla liberazione di acido ialuronico, un importante compo- 
nente del tessuto cartilagineo in grado di indurre la differenziazione di cellule staminali mesenchimali in condrociti (Caplan, 2000).

$\mathrm{Si}$ è notato che i condrociti coltivati su tale scaffold secernono un'abbondante matrice extracellulare (contenente, tra l'altro collageno I, II, aggrecano e altri glicosaminoglicani), che, unita all'idratazione delle fibre dello scaffold, rendono viscoso il costrutto cellulare. Questa sorta di "colla biologica" permette l'applicazione del costrutto in assenza di sistemi di ancoraggio. È dunque possibile collocare i costrutti da innestare direttamente sulla superficie della lesione, consentendo interventi semplificati in miniartrotomia. Recentemente, è stata inoltre sviluppata una tecnica artroscopica che ha ulteriormente ridotto l'invasività e i tempi di intervento chirurgico. Sfruttando la natura viscosa del costrutto è possibile collocare lo stesso entro il difetto in forma di dischi del diametro di $10 \mathrm{~mm}$, i quali vengono posizionati fianco a fianco fino a coprire l'intera lesione. L'operazione è estremamente semplice, non vengono richieste manovre complesse (come ad esempio suture o simili) e la strumenta zio ne necessaria è quella normalmente utilizzata in interventi artroscopici (Marcacci, 2002).

Dal 1999 sono stati finora trattati circa 5.500 pazienti. L'analisi dei dati di follow-up dimostra l'efficacia della terapia, in quanto il miglioramento clinico è via via più evidente col passare del tempo, cioè con la maturazione del tessuto cartilagine o innestato (Marcacci, 2005). Nel corso dell'attività di monito raggio, numerose sono state le biopsie di second-look prelevate a scopo di indagine. Nella maggioranza dei casi sono stati trovati già a tempi precoci $(<15$ mesi post-innesto $)$ segni di evidente riformazione di cartilagine di tipo ialino, mentre in genere a 24 mesi la cartilagine rigenerata ha chiaramente consistenza ialina (Hollander, 2006). Questi risultati dimostrano come la tecnologia dell'acido ialuronico rappresenta un valido presidio di terapia avanzata per il trattamento dei difetti alla cartilagine articolare.

\section{CONCLUSIONI}

L'ingegneria dei tessuti è un nuovo ambito di ricerca che coniuga i principi e i metodi delle scienze biologiche con quelli dell'ingegneria per la realizzazione e l'amplificazione di sostituti biologici che ripristinino, mantengano o migliorino le funzioni tessutali. L'esigenza di ricorrere a tessuti ricostruiti al di fuori del corpo umano nasce dalla constatazione 
delle difficoltà e limitazioni insite nei trapianti (inclusi gli autotrapianti) e dalla scarsità di donatori.

Il tissue engineering prevede l'impiego di una o più componenti cellulari ed, eventualmente, di una componente strutturale. Le cellule produrranno, durante la fase di proliferazione in vitro, i principali componenti della matrice extracellulare ed inizieranno ad organizzarsi spazialmente riproducendo alcune caratteristiche del tessuto di origine. Dopo l'innesto, il processo di maturazione del tessuto ingegnerizzato continuerà fino a determinare la degradazione e/o integrazione della matrice polimerica di supporto e la formazione di nuove strutture (come ad esempio i vasi, portando così alla ricostituzione della parte lesa o mancante.

È quindi importante poter disporre di matrici biocompatibili che fungano da scaffold, ovvero da impalcature di supporto dentro le quali le cellule possano svilupparsi in un contesto tridimensionale, stimolandone inoltre la deposizione di matrice extracellulare.

$\grave{E}$ inoltre essenziale affinare le tecniche di coltura cellulare, in quanto le cellule necessarie nei procedimenti di ingegneria tessutale sono spesso difficilmente coltivabili, hanno complesse richieste nutrizionali, e sono molto sensibili ad una vasta gamma di agenti lesivi. Il suo sviluppo, tuttavia, dipende in larga misura dalla comprensione della necessità di una sempre più proficua collaborazione tra diverse figure professionali (e.g. biologo, chirurgo, biologo molecolare, ingegnere dei biomateriali, fisico, ingegnere chimico) che fino ad ora hanno spesso lavorato in maniera del tutto autonoma.

La cute e la cartilagine sono i primi prodotti, frutto delle tecniche di tissue engineering, ad essere entrati nella pratica clinica consolidata per far fronte alle rilevanti necessità cliniche nei settori delle ustioni, delle ulcere croniche di difficile guarigione e delle malattie degenerative della cartilagine. Ėinteressante notare inoltre come, nel corso degli anni, si sia passati da sistemi colturali semplici privi di scaffold, a costrutti ingegnerizzati nei quali il substrato tridimensionale riveste un ruolo di fondamentale importanza.

Fidia Advanced Biopolymers è leader in questo settore con TissueTech Autograft System ${ }^{\text {тм }}$. Ad oggi più di 10.000 pazienti hanno beneficiato della nostra tecnologia dell'acido ialuronico.

Attualmente disponiamo di sofisticate tecniche colturali che consentono di ottenere, in vitro, sufficienti quantità di cellule da utilizzare come allo- o auto-innesti. Nella messa a punto di scaffold "intelligenti", in grado 
cioè di modulare le loro caratteristiche chimico-fisiche e biologiche in funzione del livello di integrazione tessutale raggiunta dal costrutto ingegnerizzato, il contributo della ricerca e dell'industria italiana è stato sicuramente determinante tanto che la produzione di questo settore d'avanguardia occupa un posto rilevante nel panorama internazionale.

\section{BIBLIOGRAFIA}

Langer $\mathrm{R}$ and Vacanti JP. Tissue engineering. Science 14: 260(5110): 920-6, 1993.

Skalak R e Fox CF (1988). Tissue engineering. Proceeding of a workshop held at Granlibakken, Lake Tahoe, Califomia, February 26-29, 1988. New York: Alan Liss.

Donati L, The clinical use of cultured keratinocyte sheets grafts: the Milan experience. In: Cultured human keratinocytes and tissue engineered skin substitutes. A cura di Horch R., Achauere B. e Munster A. Georg Thieme Veriag editore, Stoccarda, 2001.

Goodbey WT e Atala A. In vitro systems for tissue engineering. Ann NY Acad Sci 961: 10-26, 2002.

Cima LG, Vacanti JP, Vacanti C, Ingber D, Mooney D, Langer R. Tissue engineering by cell transplantation using degradable polymer substrates. J Biomech Eng. May: 113(2): 143-51, 1991

Campoccia D, Doherty P, Radice M, Brun P, Abatangelo G, Williams DF. Semi synthetic resorbable materials from hyaluronan esterification. Biomaterials 19: 2101-2127, 1998.

Caplan AI. Tissue engineering designs for the future: new logics, old molecules. Tissue Engineering 6(1): 1-8, 2000.

Vunjak-Novakovic G, Martin I, Obradovic B, Treppo S, Grodzinsky AJ, Langer R, Freed LE. Bioreactor cultivation conditions modulate the composition and mechanical properties of tissue-engineered cartilage. J Orthop Res. Jan: 17(1): 130-8, 1999.

Faglia E. Protocollo di impiego dei sostituti cutanei autologhi nel trattamento delle ulcere del piede diabetico. "Medicina Ospedaliera", supplemento CEPI - AIM Group, 2002.

Murray E. Surgery of the soul. Science History Publications, Nantucket, Mass, 2001. 
Donati L, Vaienti L, Donati V, Donati T. Ingegneria tessutale. Collana monografica di chirurgia plastica. Monduzzi editore, Bologna, 2003.

Abatangelo G e Weigel PH. New frontiers in medical sciences: redefining hyaluronan. Excerpta Medica. International Congress Series 1196 - Elsevier, 2000.

West DC, Hampson IN, Arnold F, Kumar S. Angiogenesis induced by degradation products of hyaluronic acid. Science 228: 1324-26, 1985.

Andreassi L, Casini L, Donati L. Human keratinocytes cultured on membranes composed of benzyl ester of HA suitable for grafting. Wounds 3: 116-126, 1991.

Rheinwald JG e Green H. Serial cultivation of strains of human epidermal keratinocytes: the formation of keratinizing colonies from single cells. Cell 6: 331-344, 1975.

Harris PA, Leigh M, Navsaria HA. Pre-confluent kertinocyte grafting: the future for cultured skin replacements. Burns 24: 591-593, 1998.

Chen WYJ e Abatangelo G. Functions of hyaluronan in wound repair. Wound Rep Reg 7,79-89, 1999.

Caravaggi C, De Giglio R, Pritelli C, Sommaria M, Dalla Noce S, Faglia E, Mantero M, Clerici G, Fratino P, Dalla Paola L, Mariani G, Mingardi R, Morabito A. HYAFF 11-based autologous dermal and epidermal grafts in the treatment of noninfected diabetic plantar and dorsal foot ulcers: a prospective, multicenter, controlled, randomised clinical trial. Diabetes Care: 26, 2853-2859, 2003.

Uccioli L et al. A clinical investigation on the characteristics and outcomes of treating chronic lower extremity wounds using the TissueTech Autograft System. Lower Extremity Wounds: 2(3), 140-151, 2003.

Peterson L. Articular cartilage injuries treated with autologous chondrocyte transplantation in the human knee. Acta Orthop Belg 62(suppl 1): 196200, 1996.

Buckwalter JA, Rosenberg LC, Hunziker EB. Articular cartilage: composition, structure, response to injury, and methods of facilitating repair. in Articular cartilage and knee joint function: basic science and arthroscopy. New York NY: Raven Press: 19-56, 1990.

Buckwalter JA e Mankin HJ. Articular cartilage. Degeneration and osteoarthrosis, repair, regeneration and transplantation. Bone Joint Surg 79A: 612-32, 1997. 
Minas T e Nehrer S. Current concepts in the treatment of articular cartilage defects. Orthopedics 20(6): 525-38, 1997.

Grande DA, Pitman MI, Peterson L. The repair of experimentally produced defects in rabbit articular cartilage by autologous chondrocyte transplantation. Orthop Res 7(2): 208-18, 1989.

Minas T e Peterson L. Advanced techniques in autologous chondrocyte transplantation. Clin Sports Med 18(1): 13-44, 1999.

Grigolo B, Lisignoli G, Piacentini A. Evidence for redifferentiation of human chondrocytes grown on a hyaluronan-based biomaterial (HYAFF-11): molecular, immunohistochemical and ultrastructural analysis. Biomaterials 23(4): 1187-95, 2002.

Marcacci M, Zaffagnini S, Kon E. Arthroscopic autologous chondrocyte transplantation: technical note. Knee Surg Sports Traumatol Arthrosc 10(3): 154-9, 2002.

Hollander AP, Dickinson SC, Sims TJ, Brun P, Cortivo R, Kon E, Marcacci M, Zanasi S, Borrione A, De Luca C, Pavesio A, Soranzo C, Abatangelo G. Maturation of tissue engineered cartilage implanted in injured and osteoarthritic human knees. Tissue Engineering: 12(7): 1787-98, 2006.

Marcacci M, Berruto M, Brocchetta D, Delcogliano A, Ghinelli D, Gobbi A, Kon E, Pederzini L, Rosa D, Sacchetti GL, Stefani G, Zanasi S. Articular cartilage engineering with Hyalograft C: 3 -year clinical results. Clin Orthop Relat Res.: (435): 96-105, 2005. 